\title{
A percepção da prática pedagógica pelo discente de matemática do
} PARFOR

\author{
The perception of pedagogical practice by PARFOR's mathematical \\ discovery
}

\section{Percepción de la práctica pedagógica por el discípulo de matemática del}

PARFOR

\author{
Francisco Willams Campos Lima ${ }^{2}$ \\ Emina Marcia Nery dos Santos ${ }^{3}$
}

\begin{abstract}
Resumo: Esta pesquisa foi feita no Pará, estado da Região Amazônica, de 2010 a 2013, durante o período de realização da formação de professores em Licenciatura em Matemática no âmbito do Programa de Formação de Professores da Educação Básica (Parfor). O objetivo é compreender a percepção dos sujeitos em relação à prática pedagógica a partir de suas experiências e vivências como estudantes do Programa. Concluiu-se que, em relação aos elementos da prática pedagógica, os professores-estudantes demonstraram certo nível de criticidade, ao mesmo tempo em que procuravam reconhecer em sua experiência como discentes as realidades que apresentavam correlação com o contexto no qual sua prática profissional é desenvolvida na educação básica.
\end{abstract}

Palavras-chave: Programa de formação de professor. Percepção da prática pedagógica. Perfil do professorEstudante.

\begin{abstract}
It is a research done in one of the States of the Amazon Region from 2010 to 2013 during the period of teacher training in Mathematics Degree where Parfor was implemented and fundamentally aimed to understand the perception of the subjects in relation to the pedagogical practice, based on their experiences and experiences as students of the said Program. It was concluded that, in relation to the elements of the pedagogical practice identified by the research, the student teachers demonstrated a certain level of criticism, while trying to recognize in their experience as students, realities that correlated with the context where their professional practice is developed in basic education.
\end{abstract}

Keywords: Teacher training program. Perception of pedagogical practice. Profile of student teacher.

Resumen: Esta investigación fue realizada en Pará, estado de la región Amazónica, de 2010 a 2013 durante el período de formación del profesor en Licenciatura en Matemática donde se implantó el Parfor y se objetivó, fundamentalmente, comprender la percepción de los sujetos, práctica pedagógica, a partir de sus experiencias y vivencias como estudiantes del mencionado Programa. Se concluyó que, en relación a los elementos de la práctica pedagógica, identificados por la investigación, los profesores-estudiantes demostraron cierto nivel de criticidad, al mismo tiempo que buscaban reconocer, en su experiencia como discentes, realidades que presentaban correlación con el contexto donde su la práctica profesional se desarrolla en la educación básica.

Palabras clave: Programa de formación de profesor. Percepción de la práctica pedagógica. Perfil del profesorestudiante.

\footnotetext{
${ }^{1}$ Submetido em: 25 maio 2018 - Aceito em: 20 nov. 2018 - Publicado em: 18 fev. 2019.

${ }^{2}$ Universidade do Estado do Pará (UEPA) - E-mail: willamscampos@ yahoo.com.br

${ }^{3}$ Universidade Federal do Pará (UFPA) - E-mail: emina@ufpa.br
} 


\section{Introdução}

A presente pesquisa se concentrou no Pará, um dos estados da região amazônica, onde foi implantado o Programa Nacional de Formação de professores da Educação Básica (PARFOR) para atendimento à expressiva demanda de formação inicial. O recorte temporal consiste em 2010 a 2013, correspondendo ao período de duração da formação de professores em Licenciatura em Matemática ao abrigo do programa. Do ponto de vista acadêmico, a relevância deste recorte está em permitir compreender os desdobramentos dessa política de formação no cenário amazônico, já que este se configura como a única oportunidade de efetivação do direto à educação para esses trabalhadores. Ressalta-se que os dados coletados e apresentados neste ensaio não objetivaram caracterizar a realidade como um todo, mas apresentar uma amostra que permitisse a análise e a reflexão sobre a formação docente como direito humano e sua repercussão na prática pedagógica.

Assim, foram definidos como público-alvo professores-estudantes matriculados no mencionado Curso, no primeiro semestre de 2010, em um dos polos de formação da Universidade Federal do Parái. Nos polos, os pesquisadores tiveram a oportunidade de se inserir nessa dinâmica organizativa por um período maior, estando na condição de professores-formadores, o que os instigou a empreender a presente investigação.

Nessa perspectiva, adotaram uma postura prático-reflexiva, aproximando-se da proposta formulada por Maroy (2009), que possibilita ao professor adaptar-se às situações de ensino, mediante a análise de suas práticas e resultados. Desse modo, ao se interrogarem sobre suas próprias concepções e práticas pedagógicas, sentiram-se motivados a envolver os discentes do Programa de Formação na sua conduta crítico-reflexiva, permitindo a ampliação de seu horizonte de análise sobre a realidade investigada, considerando principalmente o fato de se encontrarem diante de uma turma de professores-estudantes em cuja atividade docente a formação teria importantes repercussões.

Para tanto, foi estabelecida como questão-problema: como os professores-estudantes de matemática avaliam a prática pedagógica do Programa de Formação? Dessa forma, objetivou-se, fundamentalmente, compreender a percepção dos sujeitos em relação à prática pedagógica a partir de suas experiências e vivências como estudantes do Programa de Formação de Professores da Educação Básica.

Com o intuito de revelar o fenômeno investigado, com base no objeto de investigação, empreendeu-se uma pesquisa qualitativa, cuja coleta de dados se deu por meio: a) da aplicação de entrevistas semiestruturadas com três professores-estudantes do mencionado curso; e b) de questionários envolvendo todos os sujeitos matriculados e que cursavam regularmente o Programa, desde sua implantação no Polo já informado.

O tratamento dos dados qualitativos foi feito por meio da análise de conteúdo, partindo-se da premissa de que "por detrás do discurso aparentemente simbólico e polissêmico esconde-se um sentido que convém desvendar" (BARDIN, 1977, p. 14). Nesse sentido, buscou-se compreender os aspectos subjacentes aos discursos nas entrevistas com os interlocutores e pela aplicação dos questionários. Nessas circunstâncias, os sujeitos puderam 
manifestar-se sobre suas principais impressões acerca da prática pedagógica, tendo como ponto de partida a experiência vivenciada no contexto do Parfor, por meio de sua inserção como professores-estudantes.

\section{Programa emergencial para suprir a carência de professores no país e no Pará}

Criado pelo Ministério da Educação, o Parfor se define como um programa emergencial de modalidade presencial, instituído para atender ao disposto no artigo 11, inciso III, do Decreto ${ }^{\circ}$ 6.755, de 29 de janeiro de 2009 (BRASIL, 2009).

A implantação desse Programa vem se dando em regime de colaboração entre a Coordenação de Aperfeiçoamento de Pessoal de Nível Superior (Capes), estados, municípios, Distrito Federal e as Instituições de Educação Superior (IES), com a definição das incumbências de cada um dos entes federados e instituições/órgãos envolvidos. Tal iniciativa se destina à oferta de cursos de licenciatura e de formação pedagógica. Em linhas gerais, estabelece que seu principal desafio consiste em: "Induzir e fomentar a formação inicial e continuada de professores, na perspectiva de valorizar a carreira docente e de buscar a qualidade da educação no Brasil [...]” (BRASIL, 2012, p. 208).

A operacionalização dos Cursos oferecidos pelo Parfor ocorre mediante a divulgação de um calendário específico, em que constam as suas principais atividades. Trata-se, por conseguinte, de uma organização interinstitucional, envolvendo os diversos entes federados.

Para concorrer às vagas que são ofertadas anualmente, os professores-alunos precisam atender aos seguintes requisitos básicos: a) realização do cadastro e pré-inscrição na Plataforma Freire; b) cadastro no Educacenso na função Docente ou Tradutor Intérprete de Libras na rede pública de educação básica; e c) pré-inscrição validada pela Secretaria de Educação ou órgão equivalente a que estiverem vinculados.

Os resultados indicam que o valor agregado à formação docente pelo Parfor é considerado significativo, uma vez que o quantitativo de alunos atendidos até 2016 é expressivo, tratando-se de 36.871 professores cursando licenciatura e 34.549 formados, conforme dados fornecidos pelo Instituto Nacional de Estudos e Pesquisas Educacionais Anísio Teixeira (INEP). Apesar disso, as bases de dados disponíveis não demonstram o déficit apresentado no início do Programa e que persistem ainda hoje, mesmo com a expansão das redes educacionais em todo o país e, em especial, em territórios amazônicos.

\section{As peculiaridades do PARFOR na Amazônia: o curso de licenciatura em matemática no estado do Pará}

A precária formação de professores é um problema comum a todas as unidades da federação, apresentando-se como crônico quando se analisa a política educacional brasileira, pois se constitui em uma situação histórica e persistente. Diante desse contexto, a realidade é 
ainda mais desafiadora na região amazônica, mais especificamente no estado do Pará - em 2011, por exemplo, enquanto a média nacional de professores com formação superior era de $68,9 \%$, ela correspondia a 46\% no Pará, conforme dados disponibilizados pelo INEP.

Assim, de acordo com o Plano Decenal de Formação Docente do Estado do Pará, constatava-se a existência de mais de 60.000 docentes com qualificação inadequada, "sendo que destes, quase 40.000 não possuem curso superior, enquanto apenas 12.300 possuem licenciatura adequada à função que exercem" (PARÁ, 2009).

Em 2009, a avaliação feita pelo Fórum Estadual para Formação de Professores da Educação Básica do Pará (Forprof) acerca dessa situação concluía que a precária formação docente teria interferido diretamente no Índice de Desenvolvimento da Educação Básica (IDEB), o que motivou a oferta de cursos de licenciaturas em diferentes áreas do currículo como possibilidade de melhoria no quadro de qualificação dos professores.

Nesse contexto, ressalta-se a expressiva demanda de professores licenciados em Matemática, área considerada estratégica para alavancar os resultados do IDEB, em especial na Rede Pública de Ensino do Pará, onde se constatam indicadores ainda considerados pouco significativos- que se explicam, por exemplo, pelos altos índices de evasão e de reprovação na educação básica. Todavia, a implantação das turmas do Parfor no Pará não considerou diretamente esse fator, sobretudo, quando se analisa especificamente o desempenho dos municípios, uma vez que outras variáveis se interpuseram nesse processo de definição das sedes ou polos para atendimento das turmas, quais sejam: infraestrutura mais adequada para o funcionamento das turmas, aspecto este resultante de acordos firmados com os municípios; adesão ao Programa, por meio da inscrição prévia dos alunos-professores, entre outros (PARÁ, 2009).

Assim, quando se consideram o número de turmas atendidas e o total de alunos em formação, os dados demonstram que, de 2009 até o $1^{\circ}$ semestre de 2010, houve uma expressiva elevação em diferentes áreas do conhecimento, representando aumento de aproximadamente $750 \%$. Porém, a curva de crescimento começa a declinar a partir do $2^{\circ}$ semestre de 2010, em razão do atendimento à demanda informada na Plataforma pelo estado do Pará, havendo assim a manutenção de uma média em torno de 1300 alunos por semestre.

Gráfico 1. Evolução das matrículas no PARFOR/UFPA por etapas de 2009 a 2013

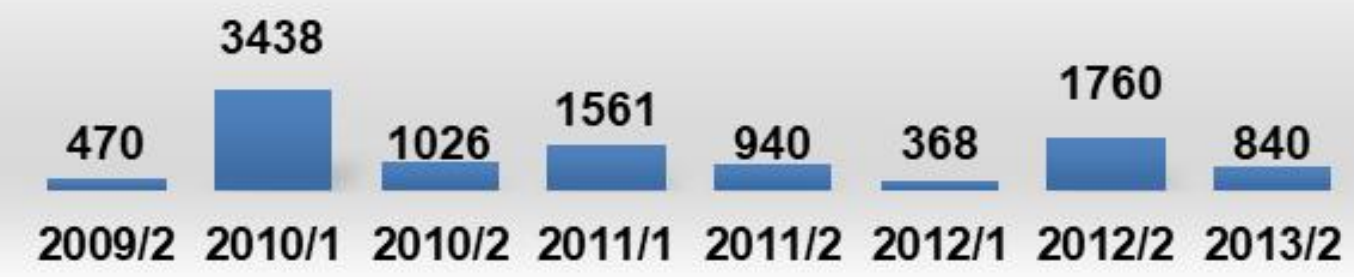

Fonte: Parfor UFPA (2013).

Diante desse contexto, o propósito fundamental da presente pesquisa consiste em demonstrar mais diretamente o atendimento efetivado em relação à Licenciatura em 
Matemática, conforme Tabela 1, haja vista que a proposta deste trabalho considerou como público-alvo de investigação os professores-estudantes de uma das turmas do Parfor, do Curso de Licenciatura em Matemática, ofertado pela Universidade Federal do Pará (UFPA), a partir do segundo ano de implantação do Programa - portanto, primeiro semestre de 2010.

Por conseguinte, no que concerne à oferta, especificamente da Licenciatura em Matemática em todo o estado do Pará, podem ser constatados os seguintes números (Tabela 1) - que não significam que houve superação da escassez de professores nesta área, haja vista que representam em torno de $13 \%$, quando se considera a média de atendimento dos últimos quatro anos analisados, conforme demonstrado anteriormente.

Tabela 1. Comparativo Atendimento do Parfor no Estado do Pará no período de 2009 a 2012

\begin{tabular}{|c|c|c|c|c|}
\hline \multirow{2}{*}{ Ano } & \multicolumn{2}{|c|}{ Outros Cursos } & \multicolumn{2}{|c|}{ Matemática } \\
\hline & $\mathbf{N}^{0}$ Turmas & $\mathrm{N}^{0}$ de Alunos & $\mathbf{N}^{\mathbf{0}}$ Turmas & $\mathbf{N}^{0}$ de Alunos \\
\hline 2009 & 14 & 470 & 03 & 103 \\
\hline 2010 & 125 & 4.464 & 24 & 888 \\
\hline 2011 & 68 & 2.501 & 04 & 112 \\
\hline 2012 & 26 & 840 & 06 & 223 \\
\hline Total & 287 & 10.403 & 37 & 1326 \\
\hline
\end{tabular}

Fonte: Elaborado pelos autores.

Não obstante haver números que evidenciem o desempenho do Parfor no Pará, nesse período de quatro anos, permanece o questionamento sobre a qualidade dos processos formativos desenvolvidos junto aos professores-estudantes que frequentaram as turmas demonstradas, por meio da Tabela 1.

Compreende-se, assim, que o mencionado Programa realiza uma política compensatória de formação, destinada à reparação de uma dívida histórica do Sistema Educacional Brasileiro em relação à formação de professores que precisariam já estar devidamente habilitados para desempenhar suas funções na educação básica.

Em que pesem os resultados obtidos pelo Parfor, é preciso compreender que eles se dão em um contexto socioeconômico baseado em políticas neoliberais, cujo enfoque fundamental é a produção de resultados eficientes, para tornar a educação básica mais competitiva e próxima dos padrões internacionais ${ }^{\mathrm{ii}}$ considerados mínimos para o desenvolvimento econômico do país. A aposta, por conseguinte, consistiria em investir na formação de professores para correção também do problema do fluxo escolar, que coloca o Brasil entre as piores nações do mundo, caracterizado por resultados insatisfatórios em termos de investimentos educacionais.

Assim, essa perspectiva de formação, por mais necessária e urgente que seja, considerando os números acima, não é suficiente para resolver o agravamento dos problemas sociais, evidenciado pelas precárias condições do Sistema Educacional Brasileiro e dos contextos nos quais os professores-estudantes se encontram inseridos. Nesse sentido, argumenta-se que os programas de formação precisariam vir acompanhados de outras 
políticas sociais, que possibilitassem ao professor-estudante condições mais adequadas de continuidade à formação inicial oferecida pelo Parfor.

Os dados que serão analisados na seção seguinte demonstram, em termos políticos e sociais, as condições que os professores-estudantes reúnem para desempenhar seu papel no cotidiano das escolas que se encontram situadas em regiões economicamente menos favorecidas do território paraense. Sua prática pedagógica é desenvolvida nesse contexto e reflete as contradições que caracterizam o modelo de produção capitalista, caracterizado em Peroni e Caetano (2015) pela precarização do trabalho docente, falta de estabilidade e de plano de carreira, além de recebimento de bolsa, em vez de salário.

\section{Entre o discurso e a prática dos professores-estudantes: o que revelaram os dados}

\section{O perfil dos professores-estudantes}

A pesquisa se concentrou sobre o universo de 34 professores-estudantes, matriculados no Parfor de Matemática, oferecido pela Universidade Federal do Pará, em um de seus Polos, abrangendo o mesmo período do respectivo curso: 2010-2013.

Assim, os dados alusivos ao perfil revelaram que 76,48\% dos entrevistados informaram ser do gênero masculino, e 23,52\% informaram ser do gênero feminino. Este dado leva a compreender que, além de a presença masculina ser maior, faz ainda perdurar o discurso ideologizado de que "as mulheres ainda não têm afinidade com os números" (Entrevistado 2), segundo a fala de um dos entrevistados. Portanto, a "masculinização iii", dos cursos ligados à área de Exatas pode significar ainda a hegemonia de um discurso de cunho machista, atrelado à suposta superioridade de gênero - tratando-se de um equívoco, pois as conquistas das mulheres em todas as áreas comprovam-nos exatamente o contrário do que vem sendo apregoado por essa ideologia, cujas origens estão nos princípios da sociedade patriarcal (MOORE JUNIOR, 1957).

Em relação à faixa etária, os dados colhidos por meio dos questionários mostram a ocorrência de: 52,94\% na faixa etária de 20 a 30 anos; e 41,17\% entre 31 e 40 anos. Assim, os achados da pesquisa comprovam que a maioria desse público já se encontra fora da faixa etária desejável para cursar a educação superior, algo configurado por razões constitutivas de uma problemática social e educacional, como a escassez de vagas nas instituições públicas de educação superior, o que pode ser comprovado pela fala de um dos entrevistados:

Falta de oportunidade para ingressar na educação superior; compromissos conjugais no início da juventude, fazendo com que o sonho de conquista do curso superior pudesse ser postergado ou adiado (ENTREVISTADO 1).

Quando se buscou compreender o comportamento dos entrevistados em relação à situação conjugal, constatou-se que $41,17 \%$ informaram ser casados, enquanto $47,05 \%$ se revelaram solteiros. Estes dados demonstram um aparente equilíbrio entre solteiros e casados, 
embora a pesquisa não pretendesse o aprofundamento desse dado, tendo em vista que o seu escopo se voltava também para conhecer traços marcantes do perfil dos professoresestudantes. Porém, pode-se considerar que essa variável, quando relacionada à fala anterior desse interlocutor da pesquisa, corrobora o entendimento de que um expressivo número teria contraído compromisso conjugal antes de concluir a educação superior.

Em relação à escolaridade dos professores-estudantes, também levantou-se o número de anos em que os entrevistados se encontravam afastados da sala de aula (desde o término do ensino médio ou do antigo segundo grau). Assim, foi verificado que um expressivo contingente se situou no intervalo de 10 a 20 anos, representando 70,58\% dos entrevistados. Porém, um percentual não menos significativo, de $23,52 \%$, informou que só teria conseguido concluir o segmento acima mencionado havia menos de 5 anos, pelo fato de terem buscado inserção ainda mais cedo no mercado de trabalho, conforme depoimento de um dos entrevistados que diz o seguinte: "Assim que terminei o primeiro grau, não tive outra opção, fui logo trabalhar para ajudar em casa [...]” (ENTREVISTADO 2).

Outro dado ainda da pesquisa diz respeito ao tipo de formação a que os professoresestudantes teriam acesso antes de optarem pelo curso do Parfor/Matemática, tendo a maioria informado que cursou o magistério - modalidade normal $(88,23 \%)$, o que diverge de um perfil mais convencional de estudantes de cursos regulares de Matemática extensivo. Esse fato pode significar que a docência exercida nessa área teria ocorrido, sobretudo, para atender a uma demanda considerada emergencial das comunidades onde os entrevistados desenvolviam suas atividades, pois o magistério geralmente é cursado por um público feminino que tradicionalmente busca cursos na área das Ciências Humanas (BRUSCHINI, 1978; VIANNA, 2002).

Com efeito, quando a pesquisa evidenciou a "masculinização" do curso, tratada anteriormente, corroborou o entendimento de que a modalidade apresentada passou a ser uma área majoritariamente ocupada por homens, contrariando a tendência histórica verificada até então, fato este que se tornou instigante no contexto da pesquisa ${ }^{\text {iv }}$.

Em relação à prole, a pesquisa demonstrou que um número considerável de professores-estudantes informou possuir apenas 2 filhos, o que representa $41,17 \%$ do universo pesquisado, enquanto os demais grupos oscilavam entre o quantitativo de 3 ou mais de 3. Esses dados comprovam que as gerações mais jovens reduziram o número de filhos, o que pode ser explicado pelas condições socioeconômicas da sociedade brasileira, com seus impactos sobre o comportamento de populações da região amazônica.

Tal aspecto pode ser complementado, em termos analíticos, com o fator renda, haja vista que a maioria $(76,47 \%)$ informou rendimentos que chegam no máximo a 3 salários mínimos, o que significa que o público-alvo da pesquisa é considerado de baixa renda. Vale ressaltar que um dos fatores que passou a ser considerado significativo neste contexto diz respeito ao fato de alguns entrevistados informarem que precisam conciliar a docência com atividades relacionadas ao mercado informal:

Muitas vezes preciso buscar complementar os meus rendimentos com a venda de produtos que interessam muito mais às mulheres. Não dá pra contar apenas com o salário que recebo da prefeitura (ENTREVISTADO 3). 
A pesquisa procurou também compreender se os entrevistados são do estado do Pará. Os dados revelaram que um contingente expressivo é oriundo de outros estados que fazem fronteira com o território paraense. Quando questionados a respeito do local de nascimento, a maioria dos entrevistados informou que seus pais migraram para essa região do país em busca de melhores condições de sobrevivência, com a chegada dos grandes projetos de desenvolvimento da Amazônia" ${ }^{v}$. Nesse contexto, a fala do Entrevistado 4 pode ser considerada reveladora: "Lembro-me, quando bem pequeno, que precisei eu e meus irmãos acompanhar nossos pais, que estavam à procura de emprego, pois a localidade onde viviam já não oferecia mais condições adequadas".

Em termos de militância política no campo da docência, um número significativo assinalou que não tem interesse pelas questões que envolvem a sua profissão. Por esse motivo não participavam de nenhuma entidade sindical que representasse interesses de sua categoria $(52,94 \%)$; enquanto praticamente metade dos informantes sinalizou o contrário $(47,05 \%)$. Esse aspecto de aparente equilíbrio nos números sugere, por um lado, que a abstinência política pode ser explicada também pela fragilidade das entidades que ainda não conseguem alcançar um nível mais adequado de mobilização da categoria. Por outro, o número da adesão à entidade sindical pode ser um indício importante de que essa consciência de classe se encontra em processo de ascensão, em razão da sensibilização dos professores-estudantes quanto às condições de trabalho da categoria que interferem em sua prática pedagógica. Nesse sentido, as falas apresentadas a seguir passam a ser ilustrativas dessas situações:

Não tenho interesse por questão política. Tenho aversão a isso. Fiquei sabendo que o Sindicato trata muito desses assuntos, que não dão em nada, pois o governo faz o que bem entende (ENTREVISTADO 2).

Para superar as dificuldades que a gente tem enfrentado só mesmo pela organização de nossa categoria. É por isso que me interesso muito pelos temas que o Sindicato nos apresenta, especialmente, quando trata da campanha salarial (ENTREVISTADO 1).

Quando questionados se estariam filiados a algum partido político, a maioria dos entrevistados informou que não tem nenhuma vinculação $(64,70 \%)$ a legendas partidárias. Porém, um percentual considerado representativo já teria buscado essa adesão $(35,29 \%)$, indicando que essa tendência começa a crescer junto à classe dos professores-estudantes, muito embora os números ainda não sejam tão expressivos. Esses dados corroboram ainda os achados anteriores da pesquisa, quando se constatou a inexpressividade da adesão dos sujeitos a questões "políticas" que podem ter repercussões em sua prática pedagógica.

\section{A percepção dos professores-estudantes em relação à prática pedagógica}

A prática pedagógica dos professores-estudantes a partir de sua experiência e vivência no Parfor/Matemática se constitui em uma das principais dimensões de investigação da presente pesquisa, haja vista que está sendo considerada a concepção oficial de currículo dos cursos de formação de professores: 
[...] como um conjunto de valores propício à produção e à socialização de significados no espaço social e que contribui para a construção da identidade sociocultural do educando, dos direitos e deveres do cidadão, do respeito ao bem comum e à democracia, às práticas educativas formais e não formais e à orientação para o trabalho (BRASIL, 2015).

Com efeito, a prática pedagógica se constitui como a forma de materialização da proposta curricular da instituição ensinante, por meio da qual a docência é concebida como ação educativa intencional e metódica. Nesse sentido, argumenta-se que a realidade concreta dos sujeitos dá vida ao currículo e às instituições de educação, compreendidas em seus múltiplos aspectos e nas quais os processos pedagógicos se desenvolvem.

Para tanto, partiu-se do pressuposto de que, pelos repertórios de saberes advindos de suas experiências e vivências, inclusive no campo da docência, os professores-estudantes poderão contribuir para a ressignificação das práticas curriculares efetivadas nesses espaços de formação, já que estes apresentam problemáticas e singularidades que precisam ser consideradas e enfrentadas por meio de uma práxis reflexiva, na qual os sujeitos envolvidos se tornam protagonistas.

Para tanto, foram estabelecidos alguns eixos que permitiram refletir, caracterizar e analisar os reflexos dessa perspectiva de formação para a prática docente dos professoresestudantes egressos desses cursos, quais sejam: metodologias utilizadas; infraestrutura e condições de ensino-aprendizagem oferecidas pelo Parfor; e, o sistema de avaliação adotado.

A percepção desses professores-estudantes pode se converter, inclusive, em possibilidades de intervenção em sua realidade ao retornarem à sala de aula na condição de docentes, pelo fato de terem passado por um processo de formação inicial com características adequadas, resultando na efetivação de uma política de formação curricular que apresenta contradições quando se propõe à reflexão sobre a prática pedagógica.

Por um lado, o Parfor oferece possibilidades de uma atuação profissional diferenciada mediante a aquisição de novos saberes e práticas - aspectos que podem ser compreendidos como decisivos para a constituição de outra profissionalidade docente, como processo dinâmico e inconcluso. Por outro, poderá reforçar a ideia de uma formação insuficiente para conferir qualidade ao trabalho docente, pelo fato de o Parfor/Matemática se constituir num Programa com um modelo de formação que pode ser considerado "aligeirado", incapaz, portanto, de oferecer o aprofundamento de conhecimentos, saberes e práticas necessárias que possam se refletir no trabalho desenvolvido junto aos alunos da educação básica, aspecto que poderia contribuir para a elevação da qualidade do processo ensino-aprendizagem.

Nessa perspectiva, quando os professores-estudantes foram questionados a respeito das metodologias utilizadas pelo Programa, os sujeitos da pesquisa apresentaram posicionamentos divergentes, pois $30 \%$ dos entrevistados consideram que as estratégias utilizadas pelos professores contribuem para a construção de novos conhecimentos em razão da articulação teoria e prática. Todavia, um expressivo contingente (70\%) revelou que as formas de intervenção utilizadas durante o curso não concorrem diretamente para a aquisição de novos saberes e práticas, justificando que as aulas são ministradas com foco nos 
conteúdos, deixando assim de oferecer a possibilidade de aprofundamento de temáticas, consideradas relevantes para sua formação.

Os dados revelam que esse fenômeno se configurou dessa forma em razão das condições em que o trabalho dos professores foi desenvolvido durante o curso; no entanto, outras variáveis precisariam ser consideradas, o que não se constituiu em objeto da presente pesquisa. Com efeito, a aparente divergência demonstrada pelos números pode ser explicada por fatores de ordem subjetiva, embora seja possível compreender que o percentual de aproximadamente $70 \%$, passe a ser sintomático nesse contexto, indicando a inadequação das metodologias utilizadas no processo ensino-aprendizagem, ao mesmo tempo que deixa de contribuir para a formação de um professor que seja capaz de refletir sobre sua prática, de modo a se sentir responsável pela "história da construção do campo intelectual da educação e da profissão", como afirma Arroyo (2000, p. 199).

Argumenta-se que a infraestrutura e as condições de ensino aprendizagem oferecidas pelo Programa, objetos mais específicos de análise, encontram-se diretamente vinculados às metodologias, constituindo-se em fatores determinantes para o êxito e fracasso das estratégias de ensino adotadas. Entretanto, a pesquisa também buscou identificar a percepção dos sujeitos em relação a esses aspectos, a fim de compreender sua leitura crítica sobre a gestão do espaço escolar e seus reflexos sobre a prática pedagógica dos professores do Parfor/Matemática.

Os professores entrevistados apresentaram argumentos que demonstram o nível de criticidade sobre as condições oferecidas pelo Parfor, destacando problemas relacionados à logística e à infraestrutura. Assim, apontaram que, por funcionarem em escolas públicas do município Polo, as turmas não ofereciam possibilidades mais efetivas de aprendizagem em razão das condições físico-ambientais. Argumentam que:

\footnotetext{
As condições climáticas das turmas interferem em nossa aprendizagem. Há momentos em que não consigo me concentrar, sobretudo quando as aulas dos professores são muito monótonas ou que tem muitos cálculos (ENTREVISTADO $3)$.

É muito difícil para mim assistir aulas nessas salas. Às vezes me sinto na pele do meu aluno do ensino fundamental. Enfrento a mesma "dificuldade" [sic] para acompanhar o trabalho dos professores (ENTREVISTADO 1).
}

A organização do trabalho aqui do Polo fica às vezes a desejar, pois nem todas as informações que nos interessam chegam a contento. Com isso, muitas vezes somos obrigados a procurar resolver problemas relacionados ao funcionamento das turmas (ENTREVISTADO 2).

Os aspectos identificados, no relato dos sujeitos podem significar, por um lado, que um Programa de Formação precisa cuidar de um conjunto de dimensões caracterizador da prática pedagógica para que seja bem-sucedido, passando, necessariamente, pela logística e infraestrutura.

Por outro lado, pode ainda demonstrar problemas em relação à gestão, evidenciando que o regime de colaboração entre os entes federados, a fim de garantir a efetivação dessa política pública, precisaria passar por diálogo mais aprofundado em uma perspectiva 
interinstitucional, de modo que a articulação e as parcerias se refletissem na qualidade do atendimento dos sujeitos contemplados pelas ações do Parfor.

Quanto ao sistema de avaliação adotado, os professores-estudantes apresentaram aspectos que abrangem desde a relação com os objetivos das disciplinas ministradas no curso até a relação com a gestão do Programa em âmbito local. Essa perspectiva ampla pode significar que os sujeitos superam um nível de avaliação que se restringe à atribuição de uma nota e/ou conceito. É importante registrar que alguns dos entrevistados assim se posicionaram:

Compreendo que a avaliação no Parfor/Matemática ela é muito importante para a prática pedagógica, porque, por meio dela, podemos perceber como as coisas andam por aqui. Assim, é possível a gente analisar o trabalho dos professores e também daqueles que participam das atividades do Programa (ENTREVISTADO 2).

Outros, entretanto, compreendem o sistema de avaliação como um mero instrumento de aferição dos conhecimentos adquiridos em sala, embora de maneira impreciso. A esse respeito, um dos entrevistados argumentou nos seguintes termos: "A avaliação aqui só serve para nos avaliar, embora a conduta dos professores varia muito" (ENTREVISTADO 1).

Os aspectos apontados nesta seção servem de parâmetros para que se possa refletir sobre a prática pedagógica, que articula aspectos metodológicos às condições de infraestrutura. Compreendem, portanto, elementos constitutivos e constituintes do currículo escolar, sendo este concebido numa perspectiva ampla e dinâmica, que informa uma determinada perspectiva de gestão educacional.

\section{Considerações finais}

A pesquisa procurou demonstrar como os professores-estudantes de matemática avaliam a prática pedagógica no contexto do Programa de Formação de Professores da Educação Básica. Os sujeitos investigados, interlocutores da pesquisa, identificaram problemas, desafios e possibilidades que permitem repensar e mesmo ressignificar políticas de formação inicial nos cenários amazônicos, em razão de suas peculiaridades e diversidades.

Portanto, a percepção dos sujeitos em relação à prática pedagógica reflete, fundamentalmente, suas experiências e vivências como estudantes do Parfor. Trata-se de uma perspectiva de compreensão e de representação social sui generis da relação ensinoaprendizagem no contexto do Parfor. Essa leitura da prática pedagógica passa a ser engendrada quando do retorno dos professores à sala de aula na condição de estudantes, os quais deixam de se reconhecer exclusivamente como "especialistas em aprendizagem" (MAROY, 2009), para desenvolver a noção de que se tornaram aprendentes do ato de ensinar - aspecto que passaram a admitir como necessário, inclusive, na possibilidade de valorização e de ressignificação de sua identidade profissional.

Compreende-se, por conseguinte, que as vivências que fundamentaram a postura reflexiva se encontram impregnadas pelo sentido que os professores-estudantes informaram sobre o contexto histórico-cultural no qual as práticas pedagógicas foram desenvolvidas. Com 
efeito, o perfil delineado pela pesquisa demonstrou peculiaridades importantes que caracterizam os sujeitos que se encontravam na condição de discentes - embora se reconhecessem, ao mesmo tempo, como docentes, pelo fato de desenvolverem sua profissionalização em suas comunidades de origem. Podendo ser considerado um dos paradoxos da docência, esse aspecto precisa ser contemplado nos programas de formação inicial, o qual é compreendido como dilema da comunidade.

Por fim, em relação aos elementos da prática pedagógica identificados pela pesquisa, os professores-estudantes demonstraram certo nível de criticidade, ao mesmo tempo em que procuravam reconhecer em sua experiência enquanto discentes como as realidades apresentavam correlação com o contexto de desenvolvimento de sua prática profissional na educação básica, ressaltando, entre os quais, os problemas do cotidiano constituintes de seu fazer pedagógico.

\section{Referências}

ARROYO, Miguel. Ofício de mestre: imagens e auto-imagens. Petrópolis: Vozes, 2000.

BARDIN, Laurence. Análise de conteúdo. Lisboa: Edições 70, 1977.

BRASIL. Resolução n. ${ }^{\circ}$ 2, de $1^{\circ}$ de julho de 2015. Ministério da Educação, [on-line], 2015. Disponível em: https://goo.gl/GgjT2B. Acesso em: 02 fev. 2018.

BRASIL. Decreto n ${ }^{\circ}$ 6.755, de 29 de janeiro de 2009: Institui a Política Nacional de Formação de Profissionais do Magistério da Educação Básica. Capes, [on-line], 2009. Disponível em: https://goo.gl/m5VmF2. Acesso em: 09 set. 2017.

BRASIL. Diretoria de Formação de Professores da Educação Básica - DEB: relatório de gestão 2009-2012. Brasília: DEB/Capes, 2012. Disponível em: https://goo.gl/MpRP9z. Acesso em: 08 ago. 2017.

BRUSCHINI, Cristina. Mulher e trabalho: engenheiras, enfermeiras e professoras. Cadernos de Pesquisa, São Paulo, v. 27, p. 5-17, dez. 1978.

MAROY, Christian. Réforme de l'inspection et montée de la régulation par les résultats en Belgique. Incidences des instituitions, des intérêts et des idées. In: PELLETIER, Guy (Dir.). La gouvernance en éducation Régulation encadrement dans les politiques éducatives. Bruxelles: DeBoeck, 2009. p. 53-71.

MOORE JUNIOR, Barrington. As origens sociais da Ditadura e da Democracia. Lisboa: Edições Cosmos, 1957.

PARÁ. Plano Decenal de Formação Docente do Estado do Pará. Belém: SEDUC, 2009. Disponível em: https://goo.gl/tD4jWv. Acesso em: 28 ago. 2017. 
PERONI, Vera Maria Vidal; CAETANO, Maria Raquel. O público e o privado na educação Projetos em disputa? Revista Retratos da Escola, Brasília, v. 9, n. 17, p. 337-352, jul./dez. 2015.

VIANNA, Cláudia Pereira. O sexo e o gênero da docência. Cadernos Pagu, Campinas, n. 17-18, p. 81-103, 2002.

\section{Notas}

' Goianésia do Pará é município localizado no sudoeste do Pará, a 292 quilômetros de Belém, onde foi implantado um dos Polos da Universidade Federal do Pará para o funcionamento de turmas do PARFOR, desde 2009.

ii O Programme for International Student Assessment (PISA) - Programa Internacional de Avaliação de Estudantes -, que estabeleceu padrões de avaliação para os países em desenvolvimento.

iii Masculinização está sendo cunhado pelos pesquisadores para demonstrar que a presença masculina é ainda dominante em relação ao curso pesquisado.

${ }^{\text {iv }}$ Ressalta-se que a coleta de dados do Censo Escolar da Educação Básica, realizada em 2007, tornou possível conhecer com detalhes o universo de professores da Educação Básica no Brasil, constituído de 1.882.961, sendo 340.036 do sexo masculino e 1.542 .925 do sexo feminino, o que representa um pouco mais de $80 \%$ do total observado. No Estado do Pará, são registrados 65.028, sendo 16.679 do sexo masculino e 48.349 do sexo feminino, demonstrando assim que o número de mulheres corresponde a aproximadamente $75 \%$, aspecto que corrobora o entendimento quanto à feminilização na docência na Educação Básica, em todas as áreas do conhecimento.

v O Estado do Pará, situado na região amazônica, passou a ser reconhecido pelo seu potencial energético e mineral, o que despertou a cobiça do capital internacional, contribuindo para a instalação de grandes projetos econômicos destinados à produção de insumos para indústrias localizadas em outras regiões do país. 